\title{
Origin of renal myofibroblasts in the model of unilateral ureter obstruction in the rat
}

\author{
Nicolas Picard · Oliver Baum • Alexander Vogetseder • \\ Brigitte Kaissling $\cdot$ Michel Le Hir
}

Accepted: 17 April 2008 / Published online: 1 May 2008

(C) The Author(s) 2008

\begin{abstract}
Tubulo-interstitial fibrosis is a constant feature of chronic renal failure and it is suspected to contribute importantly to the deterioration of renal function. In the fibrotic kidney there exists, besides normal fibroblasts, a large population of myofibroblasts, which are supposedly responsible for the increased production of intercellular matrix. It has been proposed that myofibroblasts in chronic renal failure originate from the transformation of tubular cells via epithelial-mesenchymal transition (EMT) or from infiltration by bone marrow-derived precursors. Little attention has been paid to the possibility of a transformation of resident fibroblasts into myofibroblasts in renal fibrosis. Therefore we examined the fate of resident fibroblasts in the initial phase of renal fibrosis in the classical model of unilateral ureter obstruction (UUO) in the rat. Rats were perfusion-fixed on days 1, 2, 3 and 4 after ligature of the right ureter. Starting from 1 day of UUO an increasing expression of alpha-smooth muscle actin $(\alpha \mathrm{SMA})$ in resident fibroblasts was revealed by immunofluorescence and confirmed by the observation of bundles of microfilaments and webs of intermediate filaments in the electron microscope. Inversely, there was a decreased expression of $5^{\prime}$ nucleotidase $\left(5^{\prime} \mathrm{NT}\right)$, a marker of renal cortical fibroblasts. The RER became more voluminous, suggesting an increased synthesis of matrix. Intercellular junctions, a characteristic feature of myofibroblasts, became more frequent. The mitotic activity in fibroblasts was strongly
\end{abstract}

N. Picard · O. Baum · A. Vogetseder · B. Kaissling $(\bowtie) \cdot$ M. Le Hir Anatomical Institute, Division of Vegetative Anatomy, University of Zürich, Winterthurestr. 190,

8057 Zurich, Switzerland

e-mail: brigitte.kaissling@access.uzh.ch

M. Le Hir

e-mail: lehir@anatom.unizh.ch increased. Renal tubules underwent severe regressive changes but the cells retained their epithelial characteristics and there was no sign of EMT. In conclusion, after ureter ligature, resident peritubular fibroblasts proliferated and they showed progressive alterations, suggesting a transformation in myofibroblasts. Thus the resident fibroblasts likely play a central role in fibrosis in that model.

Keywords Kidney $\cdot$ Fibrosis $\cdot$ Fibroblast $\cdot$ Myofibroblast . Epithelial mesenchymal transition (EMT) · FSP1 · S100A4 $\cdot$ Morphology

\section{Introduction}

Tubulo-interstitial fibrosis is a landmark of chronic renal failure, regardless of the underlying disease. It has been proposed that fibrosis is not only a response to tubular injury but that it may be the main driving force of nephron loss (Remuzzi and Bertani 1998; Zeisberg et al. 2001).

The basic aspects of fibrosis are similar in various organs. The increased accumulation of matrix is associated with a change of the phenotype of interstitial cells. Myofibroblasts are found in addition to or in the place of the quiescent fibroblasts of healthy tissues (Liu 2004; Desmouliere et al. 2005; Mucsi and Rosivall 2007). Compared to quiescent fibroblasts myofibroblasts show, besides their increase of the production of matrix and of the synthesis of matrixdegrading enzymes, structural characteristics, such as frequent intercellular contacts and a unique set of cytoskeletal proteins, the most distinctive being smooth muscle $\alpha$-actin $(\alpha$ SMA) (Desmouliere et al. 2005; Hinz 2007; Hinz et al. 2007; Essawy et al. 1997).

As discussed in recent reviews myofibroblasts may have different origins, possibly depending on the organ and on 
the pathology (Desmouliere et al. 2005; Hinz et al. 2007). They may originate from the differentiation of resident fibroblasts, from bone-marrow-derived precursors which infiltrate the injured tissue or from transformation of epithelial cells, the so-called epithelial-mesenchymal transition (EMT).

The origin of myofibroblasts in the kidney has been the object of intensive research. There is evidence of a role of bone marrow-derived precursors in models of adriamycin nephropathy (Li et al. 2007) and of ischemia/reperfusion injury (Broekema et al. 2007). In contrast no significant contribution of such precursors to fibrosis was found in a murine model of unilateral ureter obstruction (UUO) (Roufosse et al. 2006). Numerous research reports and review papers discuss the role of EMT in renal fibrosis (Lan 2003; Iwano and Neilson 2004; Li et al. 2007; Mucsi and Rosivall 2007). In contrast, the possibility of a transformation of resident fibroblasts into myofibroblasts in renal fibrosis has hardly been considered. There is little information on the behavior and fate of resident fibroblasts in fibrosis in the kidney, in particular whether they proliferate and differentiate into myofibroblasts.

The aim of our present investigation was to study the morphology of cortical peritubular interstitium, with a focus on the resident fibroblasts, during the first 4 days following ureteral ligature in rats. UUO is a commonly used experimental model for inducing renal fibrosis and is furthermore of outmost clinical relevance. We choose to study the early events after ureteral ligature because in early stages the identification of cell types and their putative phenotypical changes might be better traceable than in advanced stages of fibrosis. We include in our study also the early effects of UUO on tubular epithelia.

We performed our investigation by light and electron microscopy, as well as immunofluorescence, and we included morphometric quantification of tissue components and analysis of changes in the proliferation rates of interstitial cells.

We demonstrate that resident fibroblasts progressively gain the phenotype of myofibroblasts and massively increase their rate of cell division during the first days after ureteral ligature. Our data suggest that resident peritubular fibroblasts transform to myofibroblsts and participate importantly in the development of renal fibrosis.

\section{Methods}

\section{Experimental design}

For induction of UUO male 20 Sprague-Dawley rats weighing $160 \pm 3 \mathrm{~g}$ were anesthetized using isoflurane and the abdominal cavity was opened by a midline incision.
The right ureter was tied with $4 / 0$ silk $3-5 \mathrm{~mm}$ below the renal hilum. The rats of the control group (four rats) were also laparatomized, the ureter exposed, but no ligature was made. After closure of the abdomen the animals were returned to the cage with free access to standard lab chow and water ad libitum.

The experimental procedure conformed to the Institutional Guidelines of Experimental Animal Care and Use and was approved by the Veterinary office of the Kanton Zürich.

\section{Tissue fixation}

After 1, 2, 3 and 4 days of the operation, five ureter-ligated rats were fixed by vascular perfusion through the abdominal aorta as described previously (Dawson et al. 1989). The control group was perfused on day 4 . The occluded renal pelvis was cut open just before perfusion to allow outflow of the fluid from the kidney. The fixative solution was composed of $3 \%$ paraformaldehyde, $0.01 \%$ glutardialdehyde and $0.05 \%$ picric acid in a $6: 4$ mixture of $0.1 \mathrm{M}$ cacodylate buffer (pH 7.4, adjusted to $300 \mathrm{mOsm}$ with sucrose) and $10 \%$ hydroxyethyl starch in saline (HAES steril TM; Fresenius AG, Germany). Five minutes after onset of the fixation both kidneys were removed.

\section{Light and electron microscopy}

From the unligated left and from the ligated right kidney large tissue blocks extending from the renal capsule to at least the upper third of the inner zone were immersed for at least $24 \mathrm{~h}$ in the fixative solution described above to which $1 \%$ glutardialdehyde was added. This tissue was then embedded into epoxy resin and used for light and electron microscopy. Semithin $(1 \mu \mathrm{m})$ sections and ultrathin $(80 \mathrm{~nm})$ sections were cut with an ultramicrotome. Semithin sections were stained with $1 \%$ methylene blue and $1 \%$ azure II and were studied with a Polyvar microscope (Reichert Jung, Vienna, Austria). Ultrathin sections were postfixed with osmium tetroxyde and contrasted with uranyl acetate and studied with a CM100 Philips electron microscope.

Immunofluorescence microscopy

Coronal slices across the right and left kidney, comprising the cortex and the outer medulla were frozen in liquid propane, cooled with liquid nitrogen. From these slices, 2-3 $\mu \mathrm{m}$ thick sections were cut in a cryostat (Microm, Walldorf, Germany). The sections were pre-treated with $5 \%$ normal goat serum diluted in PBS with $1 \%$ BSA, which was also the diluent for all other antibodies. They were incubated at $4^{\circ} \mathrm{C}$ overnight in a humidified chamber with primary antibodies described in Table 1 . Binding sites of 
Table 1 List of primary antibodies

\begin{tabular}{lll}
\hline Primary antibodies & Host & Source \\
\hline S100A4 & Rabbit & Dako, Glostrup, Denmark \\
Ecto-5'nucleotidase $\left(5^{\prime} \mathrm{NT}\right)$ & Rabbit & M. Le Hir \\
Ecto-5'nucleotidase $\left(5^{\prime} \mathrm{NT}\right)$ & Mouse & BD Biosciences, Franklin Lakes, NJ, USA \\
Alpha smooth muscle actin $(\alpha \mathrm{SMA})$ & Mouse & Dako, Glostrup, Denmark \\
Alpha smooth muscle actin $(\alpha \mathrm{SMA})$ & Rabbit & Abcam, Cambridge, UK \\
Rat MHC class II & Mouse & Clone OX 6 \\
Phospho-S6-kinase & Rabbit & Cell Signaling, Danvers, MA, USA \\
Collagen Type I & Mouse & MD Biosciences, Zurich, Switzerland \\
Vimentin & Mouse & Chemicon, Temecula, CA, USA \\
\hline
\end{tabular}

the primary antibodies from rabbit origin were detected using Alexa 555-conjugated goat anti-rabbit (Invitrogen, Carlsbad, CA, USA) and the primary antibody from mouse origin was detected using Alexa 488-conjugated goat anti-mouse (Invitrogen). For chromatin staining 4,6-diamidino-2-phenylindole (DAPI; Sigma, St Louis, MO, USA) was added to the secondary antibodies. The slides were mounted in DAKO-glycergel (Dakopatts, Glostrup, Denmark) containing $2.5 \%$ of 1,4-diazabicyclo (2.2.2)octane (DABCO; Sigma, St Louis, MO, USA) as fading retardant.

Sections were studied by epifluorescence with a Polyvar microscope (Reichert Jung, Vienna, Austria), and digital images were acquired with a CCD camera.

\section{Quantitative evaluation}

In order to quantify changes in the structural composition of the renal cortex and to assess the mitotic rates of interstitial cells within this area, a morphometrical analysis was undertaken on sections of kidneys from three rats in each of the five experimental groups.

In $1 \mu \mathrm{m}$ thick epon sections with a surface of approximately $2 \times 4 \mathrm{~mm}$, a randomly selected cortical area of approximately $1 \mathrm{~mm}^{2}$ was photographed at $100 \times$ magnification using a Leica DMRBE microscope (Leica Microsystems, Heerbrugg, Switzerland) connected to a Olympus SIS colorview camera (Olympus Soft imaging systems, Münster, Germany). The individual micrographs were merged to one large image and the exact size of the total image area was subsequently determined by analySIS software (Olympus Soft imaging systems, Münster, Germany).

The images were overlaid with a $15 \times 15$ grid to assign the histological structures covered by each of the 225 intersections to one of five categories, namely tubules, capillaries, interstitium, renal corpuscles and large vessels. The fractional areas of these histological structures were defined as the ratio of the number of category-specific intersections to the total number of intersections (225).

Furthermore, the total numbers of peritubular interstitial cells in the image were counted and the numbers of mitotic cells in the cortical interstitium were recorded. This allowed calculating the fraction of mitotic cells in relation to all interstitial cells. The identity of each mitotic cell in the cortical interstitium was attributed to one of the two categories "fibroblasts" or "mononuclear cells" (dendritic cells, infiltrating leucocytes) independently by two investigators. Mitotic cells that could not be assigned to one of these two categories or that were classified differently by the two investigators recorded as 'non-identified'.

\section{Statistics}

Numerical data are expressed as mean values $(n=3) \pm$ standard deviation (SD).

\section{Results}

\section{Macroscopy}

The ligature of the right ureter resulted invariably in each rat in a large expansion of the renal pelvis within the renal sinus and of the ureter above the ligature. The enlargement appeared more prominent at the first and second day after the operation than after the third and fourth day. The fluid contained in the expanded renal pelvis was clear up to the second day and appeared trouble and viscous the third and fourth day. In sham operated rats no expansion of the renal pelvis was observed.

\section{Microscopy}

\section{Tubular epithelia}

In control and contra-lateral kidneys the tubules were patent with rather homogeneous luminal diameter (Figs. 1a, 2a).

Starting from day 1 the most striking feature in tubules of kidneys with occluded ureter was the heterogeneity of tubular diameter. 
Fig. 1 Rat renal cortex of contra lateral (a, e) and of ureter ligated (b-d, f-h) kidneys; $1 \mu \mathrm{m}$ epon sections. Overviews (a-d) show the dilatation of distal segments after 1 day, the collapse and shrinkage of predominantly proximal tubules after 2-4 days and the progressive enlargement of the interstitium. Higher magnifications $(\mathbf{d}-\mathbf{h})$ reveal the increasing complexity of interstitial cells; asterisk fibroblasts; $D$ distal segment, $P$ proximal tubule (cut tangentially in $\mathrm{H}$ ); arrow fibroblast in prophase of mitosis, arrowhead mononuclear cell in mitosis. Bar a-d $\sim 100 \mu \mathrm{m}, \mathbf{e}-\mathbf{h} \sim 10 \mu \mathrm{m}$



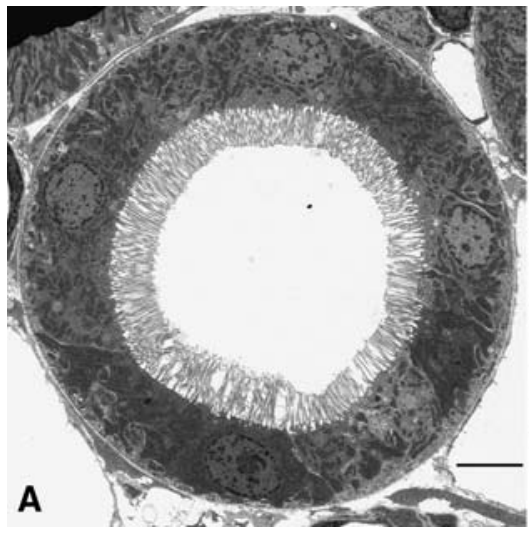

Fig. 2 Proximal tubules in the cortex of a sham operated kidney (a) and of a ureter-ligated kidney on day $3(\mathbf{b}, \mathbf{c}) .80 \mathrm{~nm}$ epon sections. In $\mathbf{b}$ and $\mathbf{c}$ the outer diameters of the tubules as well as the width of their lumina are decreased and the fractional area of nuclei in the epithelium

\section{Proximal tubules}

After 1 day (Fig. 1b) most proximal tubular profiles appeared similar as in controls, only a few proximal tubular profiles were markedly smaller in diameter than in controls. As soon as after 2 days (Fig. 1c) the majority of proximal tubules displayed narrowed lumina and decreased outer

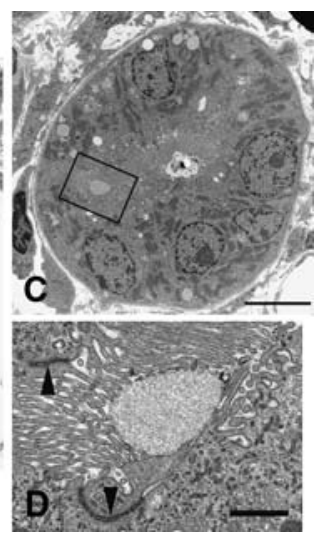

is abnormally high. d Higher magnification of the area framed in $\mathbf{c}$, revealing junctional complexes (arrowheads) and microvilli. Bars in a, b, c (same magnification): $10 \mu \mathrm{m}$; in $\mathbf{d} 1 \mu \mathrm{m}$

diameters. That tubular shrinkage progressed through the 4 days of experiment (Figs. 1d, 2). The density of nuclei was strikingly increased in shrunken tubules (Fig. 2), thus, the decreased epithelial volume reflected cellular atrophy rather than cell death. The brush border remained well visible even after nearly complete collapse of the lumen (Figs. 1g, 2c, d). Although proximal and distal tubules in 
the cortex revealed severe regressive changes no disintegration of the epithelial layer was detected either by light or by electron microscopy. In all cases the proximal tubule were lined by a continuous epithelium showing ultra-structural evidence of polarity like microvilli at the luminal aspect and morphologically intact junctional complexes. We found no instance of disruption of the tubular basement membrane. The polarized expression of $5^{\prime} \mathrm{NT}$ at the luminal pole of all proximal tubules further evidenced the preservation of epithelial architecture in proximal tubules. Tubular cell death was not conspicuous in the cortex. Mitotic cells were rather frequently observed in proximal tubules from day 2 on. At the same time epithelial cells, including mitotic cells, were occasionally seen in the lumen, indicating some degree of anoikosis. From day 3 on an increasing number of proximal tubular profiles bound anti collagen 1 -antibodies. Even in those profiles the individual epithelial cells were still recognizable.

\section{Distal segments and collecting ducts}

After 1 day dilation of the luminal diameters of most distal segments was eye-catching (Fig. 1b). Occasionally their lumen was filled with hyaline material. From day 2 on cellular hypotrophy associated with a collapsed lumen, as described above for proximal tubules, became apparent also in distal segments. At day 4 many distal profiles were massively shrunken and atrophic (Figs. 1d, h, 3). However, some profiles remained histologically almost normal up to day 4 . The diameters of collecting duct profiles were dilated from day 1 on and their largely open lumina were strikingly prominent among the shrunken tubular profiles in the cortex at day 3 and 4 (Fig. 1c, d).

\section{Quantitative estimation of changes of cortical tubular volume and peritubular spaces}

The fractional area of tubules, capillaries and the interstitium was assessed in $1 \mu \mathrm{m}$ epon sections of perfusion fixed kidneys (Fig. 4). The epithelial shrinkage of most proximal tubules and of some distal tubules was reflected in significantly decreased fractional volume of tubules from day 2 (Fig.4).

The peritubular interstitial space is defined as the space between the tubular, glomerular and capillary basement membranes. After ligature of the ureter its fractional volume increased significantly from about $11 \%$ in control kidneys (day 0 ) to more than twice this value on days 3 and 4 of UUO (Figs. 1d, 4). The fractional volume of capillaries did not change significantly (Fig. 4).

\section{Cortical peritubular interstitium}

The major cellular constituents of the peritubular interstitium are peritubular fibroblasts (Dawson et al. 1989; Gandhi et al. 1990; Kaissling and Le Hir 1994; Kaissling et al. 1996) and dendritic cells (Kaissling and Le Hir 1994; Dong et al. 2005; Soos et al. 2006). In addition a few lymphocytes and rare granulocytes may be encountered (Kaissling and Le Hir 1994). The precise delimitation of the individual interstitial cells within the narrow interstitial space is difficult in conventional light microscopic preparations. Fixation by vascular perfusion resulted in unfolded intercellular spaces and in thin sections $(80 \mathrm{~nm}$ and $1 \mu \mathrm{m}$ epon sections, $3 \mu \mathrm{m}$ cryostat sections) delimitation of the cytoplasm of individual interstitial cells is possible.

\section{Phenotypical changes of peritubular fibroblasts}

In control animals the morphology of fibroblasts (Fig. 1e) and dendritic cells was as described previously (Kaissling et al. 1996). In fibroblasts the nucleus was generally angular and surrounded by a sparse cytoplasmic rim, most organelles being located in the extended cytoplasmic processes (Figs. 1e; 5a). The latter showed connections with tubules and capillaries and to each other, as seen in electron microscopy (EM; Figs. 5a, 6b, c). Thereby fibroblasts establish a continuous framework within the peritubular
Fig. 3 Thick ascending limb in the cortex of a sham operated kidney (a) and of a ureter ligated-kidney on day $2(\mathbf{b}) ; 80 \mathrm{~nm}$ epon sections. In $\mathbf{b}$ the outer diameters of the tubule as well as the width of the lumen is decreased. $\mathbf{c}$ Higher magnification of the area framed in $\mathbf{b}$, revealing junctional complexes (arrowheads) and microvilli. Bars in a, b (same magnification): $5 \mu \mathrm{m}$, in d $1 \mu \mathrm{m}$
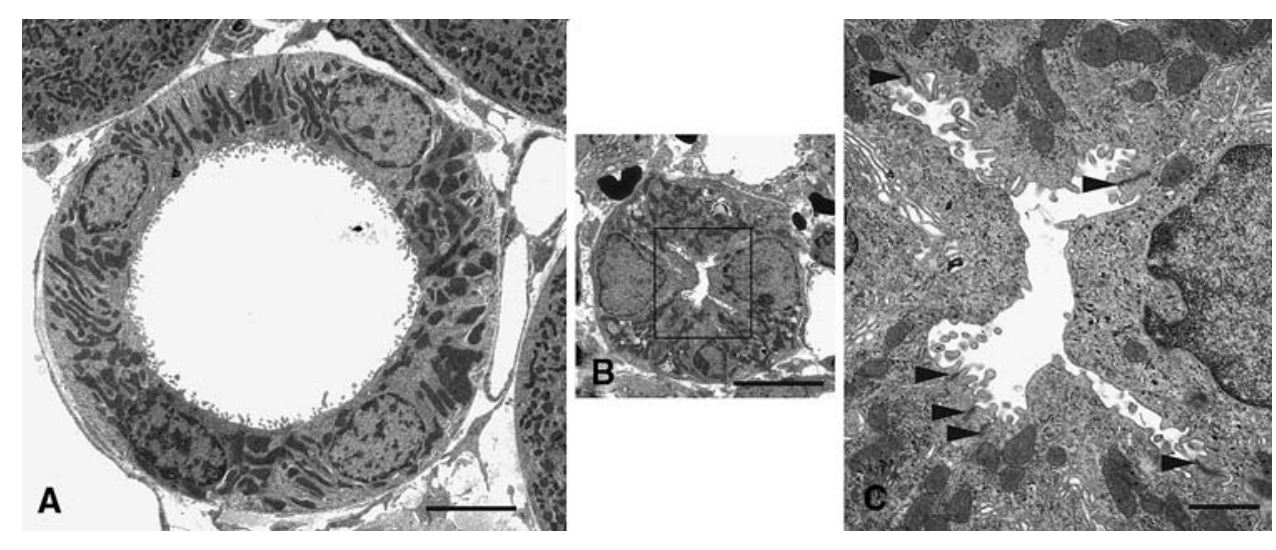


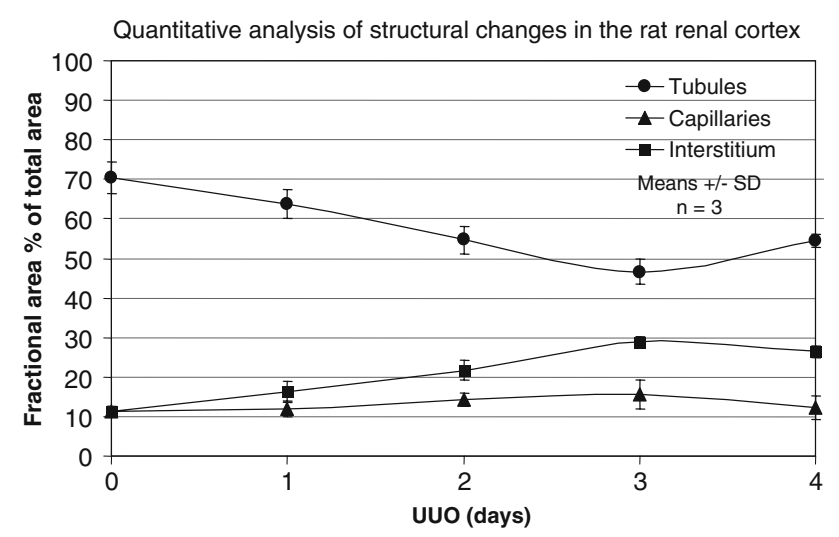

Fig. 4 Quantitative analysis of the structural changes in rat renal cortex in response to UUO. The fractional area of the tubular system decreased while that of the interstitium increased continuously during the first 3 days after UUO. Tubular and interstitial areas differ significantly from control values from day 2 on. The fractional area of capillaries did not change significantly during the 4 days of UUO. Values are means $\pm \mathrm{SD}, n=3$

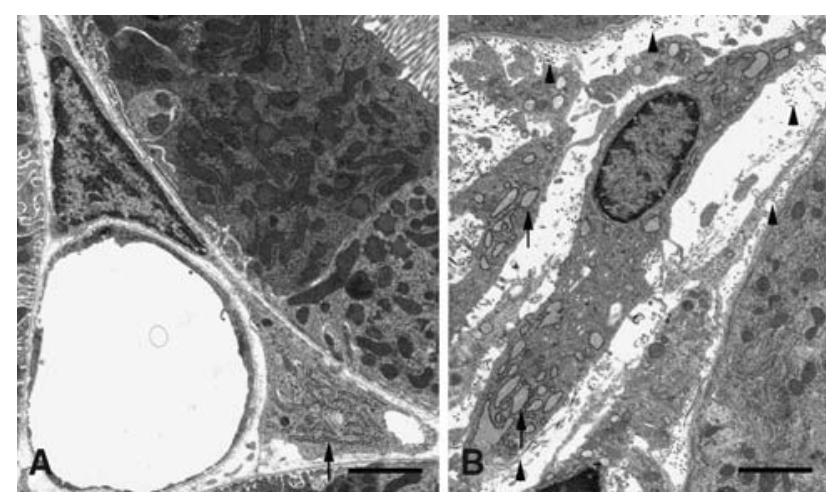

Fig. 5 Characteristic fibroblasts in a sham-operated kidney (a) and in a ureter-obstructed kidney on day 2 (b). In a the RER (arrow) is flat and concentrated in a cell process whereas the cytoplasmic rim around the angular nucleus is narrow and virtually organelle-free. The fibroblast displays the characteristic narrow association with a tubule and a blood capillary. Collagen fibrils are hardly detectable. The fibroblasts in b reveal inflated cisterns of RER (arrows) distributed all over the cytoplasm, including the direct surroundings of the oval nucleus. In B most collagen fibrils are cross-sectioned and appear as dots (arrowheads). They are abundant along the basement membranes of tubules (lower right and upper left corners). Bars in $\mathbf{a}$ and $\mathbf{b}$ (same magnification): $2 \mu \mathrm{m}$

interstitium (Kaissling and Le Hir 1994; Kaissling et al. 1996).

The most conspicuous organelles in the cytoplasm of fibroblasts were the large, mostly flattened, cisterns of rough endoplasmic reticulum (RER) (Fig. 4a). Actin filaments were found exclusively in a narrow rim of cytoplasm underlying the plasma membrane, most frequently at sites of contact with tubules and vessels (Kaissling et al. 1996).

Starting from day 1 (Fig. 1f-h) the appearance of fibroblasts became strikingly heterogeneous. Whereas a small fraction almost retained the morphology found in control kidneys, others displayed profound changes. In general the nucleus was rather rounded (Fig. 5b), often with indentations, and it was surrounded with a broad cytoplasmic rim. The cytoplasmic processes were often extensively branched (Fig. 1f-h). The RER was more abundant than in controls. In a large fraction of fibroblasts the RER cisterns were inflated and filled with flocculent material (Figs. 5b, 6c) consistent with enhanced synthesis of matrix. Indeed, massive accumulations of collagen fibrils were seen in the immediate vicinity of fibroblasts with such inflated cisterns of RER. In other cells the RER cisterns were flat (Fig. 6c) as in controls. The two forms could be found in neighboring fibroblasts (Fig. 6c) and even occasionally within a single cell (Fig. 6d). Intermediate forms of the RER were also found suggesting a progressive activation of the fibroblasts. Bundles of actin filaments were observed in the cytoplasmic processes. The presence of dense bodies (Fig. 6a) identified them as $\alpha$ SMA filaments. There was no obvious correlation between the abundance of bundles of actin filaments and the abundance or shape of the RER. In some fibroblasts of obstructed, but not of control kidneys intermediate filaments were seen (not shown). Adherent junctions between fibroblasts were sparse in controls but were common in obstructed kidneys (Fig. 6b, c).They sometimes connected a fibroblast with a flattened RER with one with an inflated RER but never a fibroblast with a mononuclear cell or two mononuclear cells with each other.

The study of the peritubular interstitium in the renal cortex by immunofluorescence takes advantage of the fact that fibroblasts in healthy kidneys of rats and mice strongly express 5'NT in their plasma membrane (Dawson et al. 1989; Kaissling and Le Hir 1994). Only a very small population of lymphocytes that are rarely encountered in the interstitium and easily distinguished from fibroblasts on account of their different shape may weakly express $5^{\prime} \mathrm{NT}$ (=CD 73) (Kaissling and Le Hir 1994).

Alpha SMA is the hallmark of myofibroblasts. In the kidney of adult healthy controls there is no trace of $\alpha \mathrm{SMA}$, as well as of vimentin (Essawy et al. 1997) in peritubular 5'NT-positive fibroblasts (Marxer-Meier et al. 1998). Alpha SMA was apparent in the peritubular interstitium as soon as after one day of ureteral obstruction. Double labeling for $5^{\prime} \mathrm{NT}$ and $\alpha$ SMA (Figs. 7,8 ) revealed that $\alpha$ SMA was localized consistently within 5'NT-positive fibroblasts (Fig. 7d-f), in agreement with the observation of bundles of actin filaments and dense bodies in fibroblasts in the electron microscope. Alpha SMA was detectable in the majority of $5^{\prime}$ NT-positive fibroblasts on day one, though in highly variable intensity, and in virtually all of them on day 4 of UUO (Fig. 8). The average intensity of immunolabeling for $\alpha$ SMA in individual fibroblasts progressively increased during the 4 days. The intensity of labeling of $5^{\prime} \mathrm{NT}$ and of $\alpha \mathrm{SMA}$ seemed to be reciprocal. In fibroblasts 

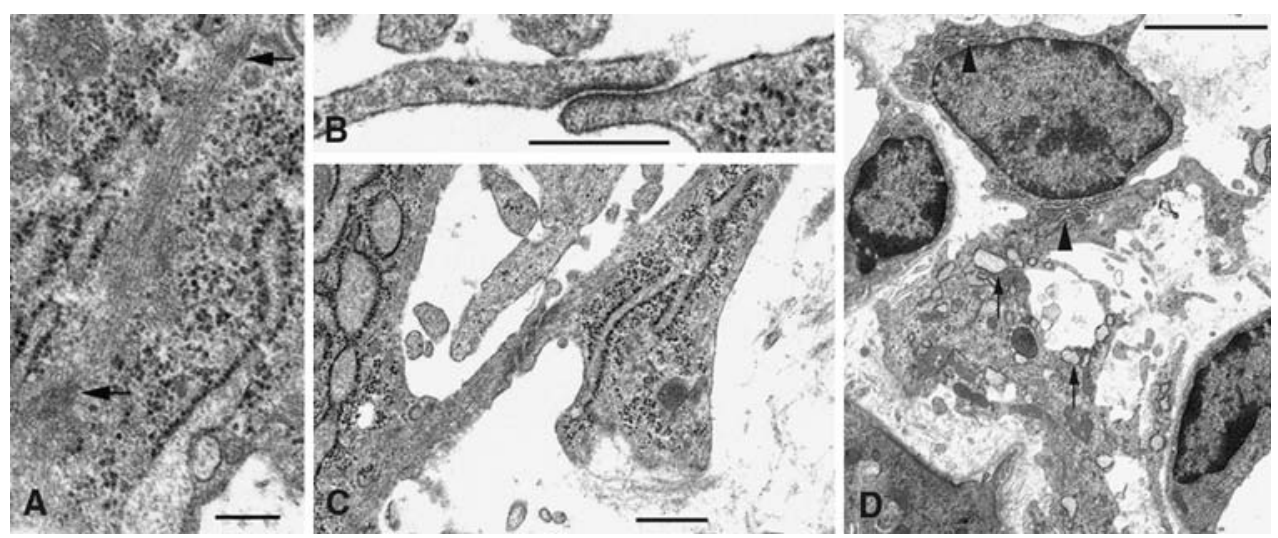

Fig. 6 Ultrastructural details of fibroblasts in ureter-ligated kidney (a-c: day 2). a A bundle of actin filaments displays dense bodies (arrows). b Adherent contact between two fibroblasts. c Intercellular contact between two fibroblasts that display different types of RER, inflated on the left, flat as in controls on the right. d Fibroblast in a ureterligated kidney (day 4). The profile of the cell reveals large irregularly formed cytoplasmic processes. Different types of RER are visible even within the same cell; in the pericaryon the cisterns are flat (arrowheads), in the large process they are inflated (arrows), masses of collagen fibrils are seen in the immediate vicinity of the process. Bars $0.5 \mu \mathrm{m}$ and in $\mathbf{d} 5 \mu \mathrm{m}$
Fig. 7 Renal cortex in shamoperated (a) and in ureter-ligeted kidneys (b, c). $3 \mu \mathrm{m}$ cryostat sections; immunofluorescence; ecto-5'nucleotidase $\left(5^{\prime} N T\right)$ red channel, alpha smooth muscle actin $(\alpha S M A)$ - green channel); chromatin staining by DAPI-blue channel. In controls (a) 5'NT strongly labels cells in the interstitium and the brush border of proximal tubules, $\alpha$ SMA labels exclusively smooth muscle cells in arterial vessels (a). In the interstitium of ureter-ligated kidneys $(\mathbf{b}, \mathbf{c})$ $5^{\prime} \mathrm{NT}$ staining decreases, whereas that of $\alpha$ SMA appears and becomes increasingly prominent. d-f interstitial fibroblast in ureter-ligated kidney after 2 days. $5^{\prime} \mathrm{NT}$ is distributed over the plasma membrane and cytoplasm in a granular manner, $\alpha \mathrm{SMA}$ is apparent along the plasma membrane and in the cellular processes. Bar $\mathbf{a}-\mathbf{c} \sim 100 \mu \mathrm{m}, \mathbf{d}-\mathbf{f}$ $\sim 10 \mu \mathrm{m}$
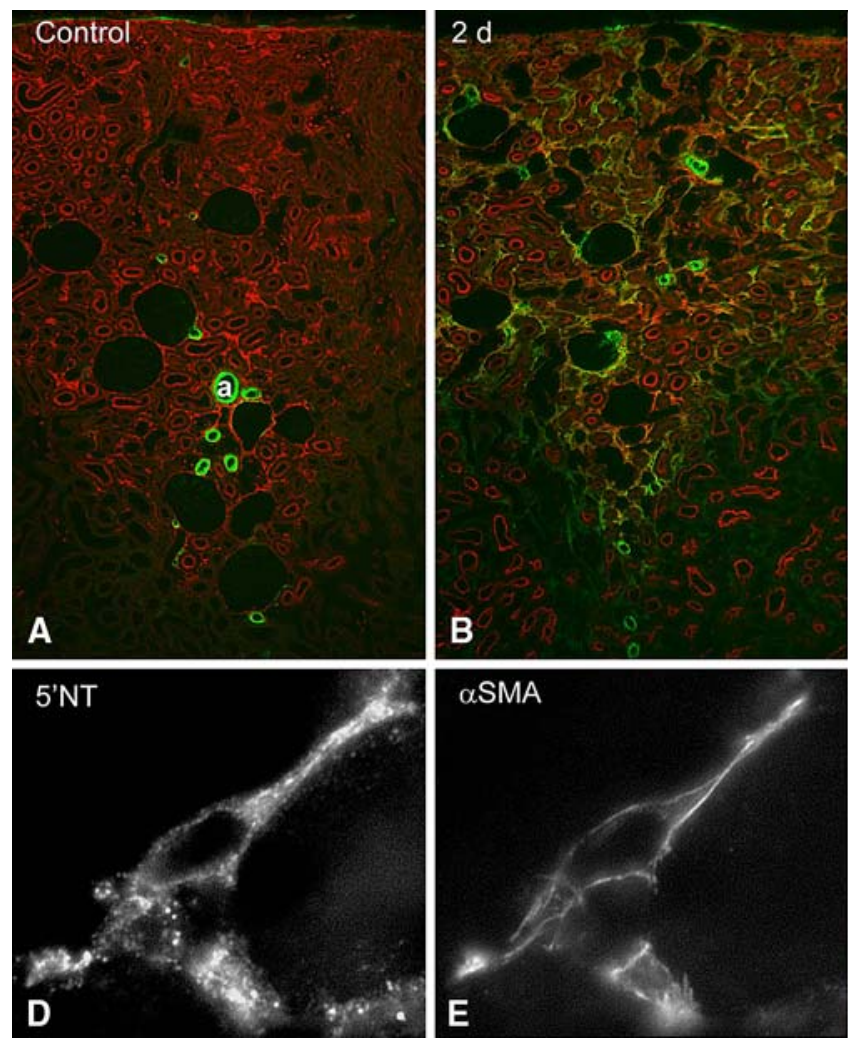
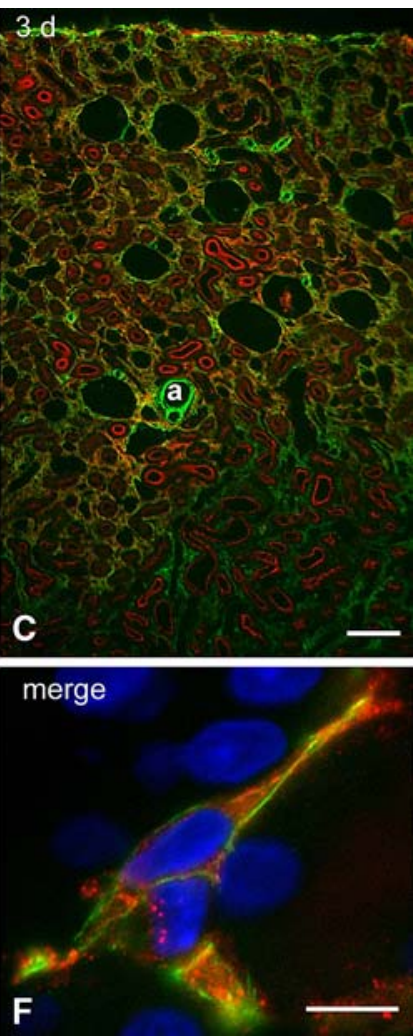

strongly positive for $\alpha$ SMA the $5^{\prime} \mathrm{NT}$ labeling was weaker than in normal fibroblasts and the staining pattern for $5^{\prime} \mathrm{NT}$ changed from a sharp outline of the plasma membrane to a slightly diffuse, granular pattern over the plasma membrane and cytoplasm (Fig. 8, see also Fig.14). Large areas with strongly $\alpha$ SMA- and weakly 5'NT-positive fibroblasts were found around shrunken tubules, whereas prominent $5^{\prime} \mathrm{NT}$ and weakly $\alpha$ SMA-positive cells were found in areas where the tubules seemed to be rather intact (Fig. 8).
Accumulation of collagen type I in the peritubular interstitium

Accumulation of collagen I ( $\mathrm{Col} \mathrm{I})$ in the interstitial space is a hallmark of renal fibrosis. Collagen type $\mathrm{I}$ is produced by (myo)fibroblasts. By immunofluorescence Col I was virtually absent in the cortical peritubular interstitial space of controls. A modest immunofluorescence was apparent along the tubular profiles. 
Fig. 8 Renal cortex after 4 days of ureter ligation; $3 \mu \mathrm{m}$ cryostat sections; immunofluorescence; ecto- $5^{\prime}$ nucleotidase $\left(5^{\prime} N T\right)$ red channel, alpha smooth muscle actin $(\alpha S M A)$ - green chan$n e l)$; chromatin staining by DAPI-blue channel. a Merge of channels, b 5'NT, c $\alpha$ SMA; the framed area 1 comprises interstitium with high $5^{\prime} \mathrm{NT}$ and faint $\alpha$ SMA staining, adjacent to rather intact tubules, the framed area 2 comprises interstitium with strong $\alpha$ SMA and faint $5^{\prime} \mathrm{NT}$ staining, adjacent to collapsed tubules. Bar a-c $\sim 100 \mu \mathrm{m} ; 1,2: 10 \mu \mathrm{m}$
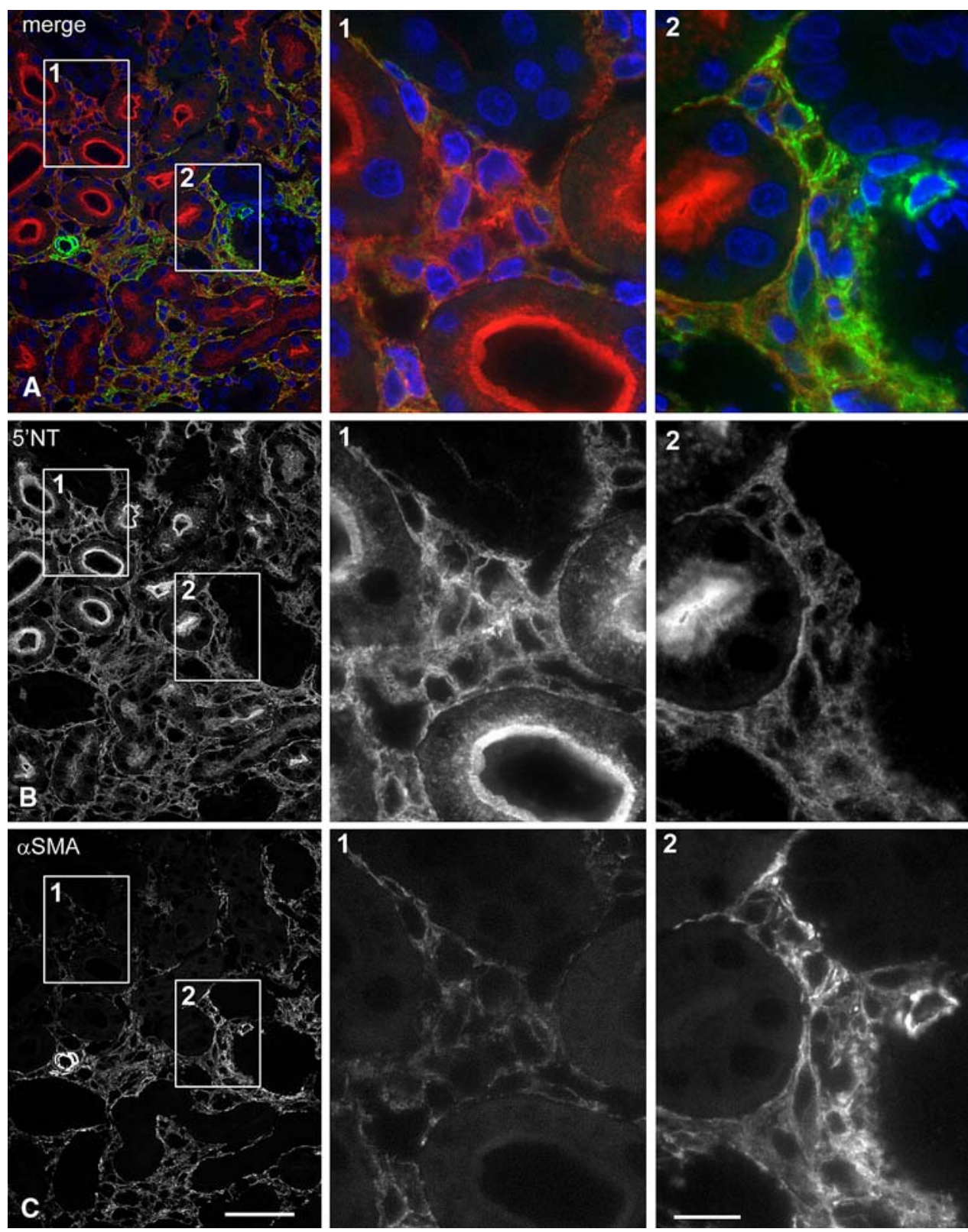

In the obstructed kidneys increasing amounts of Col I was found beginning with day 1 after ligature. In the cortex of ureter-ligated kidneys immunolabeling revealed heterogeneity in the abundance of Col I and this correlated closely with the intensity of immunolabeling for $\alpha$ SMA (Fig. 9). Thus interstitial Col I staining was the most abundant at sites with strongly $\alpha$ SMA-positive fibroblasts. At sites with moderate $\alpha$ SMA expression the collagen deposits could be attributed to single interstitial $\alpha$ SMA-positive cells (Fig. 9d, e). Col I staining became particularly strong around the tubular basement membranes of shrunken tubules, in agreement with the accumulation of collagen fibrils along the tubular basement membranes, seen in EM (Figs. 5b, 13b). Col I was more abundant in regions where the tubules were atrophic than in regions with apparently intact tubules. At these sites the tubular epithelium revealed some binding to antibodies to Col I.

\section{Increases in mononuclear cells in the cortical interstitium}

Mononuclear cells can be distinguished from fibroblasts on account of morphological criteria (Kaissling and Le Hir 1994; Kaissling et al. 1996) and in immunofluorescence by their absence of $5^{\prime} \mathrm{NT}$ and presence of specific marker proteins. In the healthy kidney the majority of mononuclear cells in the interstitial space are dendritic cells. The dendritic cells in rats can be recognized by their high expression of MHC class II. Morphologically these cells are distinguished from fibroblasts by their usually ovoid nucleus and extensive formation of cell projections that 
Fig. 9 Renal cortex after ureter ligation; $3 \mu \mathrm{m}$ cryostat section, immunofluorescence for $\alpha$ SMA - green channel and collagen type I ( Col I) - red channel; chromatin staining by DAPI-blue channel; $a$ arteriole. a-c Overview on the renal cortex after three days of ureter ligation; localization and intensity of $\alpha$ SMA and of Col I staining in the intertstitium coincide; heavy collagen deposits are seen around collapsed tubules (see also Fig. 13 where the ring of collagen is shown by TEM). $\mathbf{d}-\mathbf{f}$ : a single fibroblast with distinct aSMA under the plasmalemm and immediately adjacent collagen deposits 2 days after ureterligature. Bar $\sim 50 \mu \mathrm{m}$
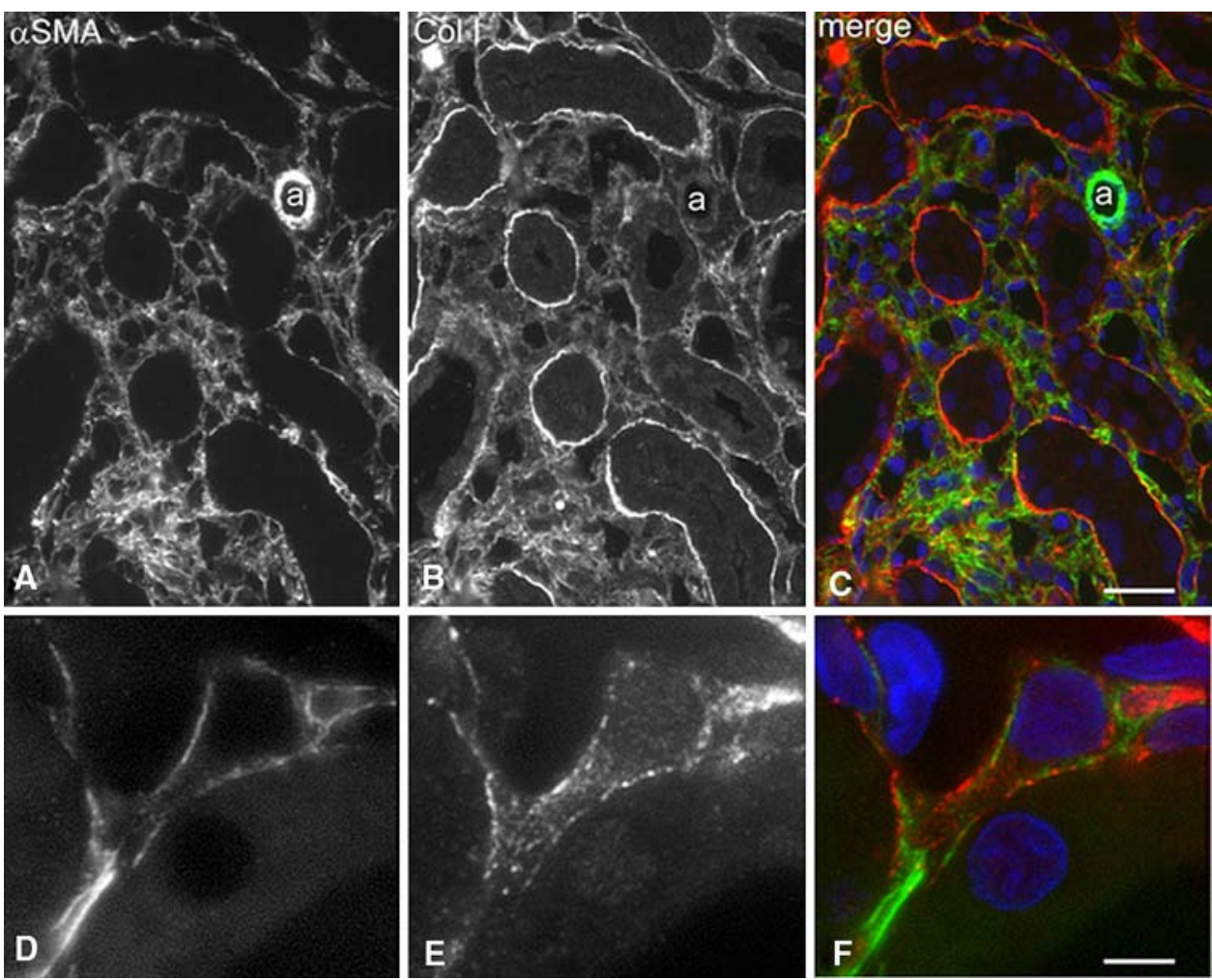

Fig. 10 MHC II-positive interstitial cells in the renal cortex. ae $3 \mu \mathrm{m}$ cryostat sections, immunofluorescence for MHC II, $\mathbf{f}$ $1 \mu \mathrm{m}$ epon section. In controls faintly stained MHC II-positive cells are present throughout the interstitial spaces, a few are seen also in the glomerulus $(G)$. The amount and size of MHC II-positive cells in the peritubular interstitium increases after 2 and even more after 4 days of ureter ligation, a few MHC II-positive cells are seen in the Glomerulus $(G)$; d-f characteristic morphology of dendritic cells (asterisks) with a smooth, rounded or ovoid nucleus and lace veil-shaped large processes; in (f) two mononuclear cells in mitosis are seen in left half. Bars $\mathbf{a}-\mathbf{c} \sim 100 \mu \mathrm{m}$; $\mathbf{d}-\mathbf{f} \sim 10 \mu \mathrm{m}$
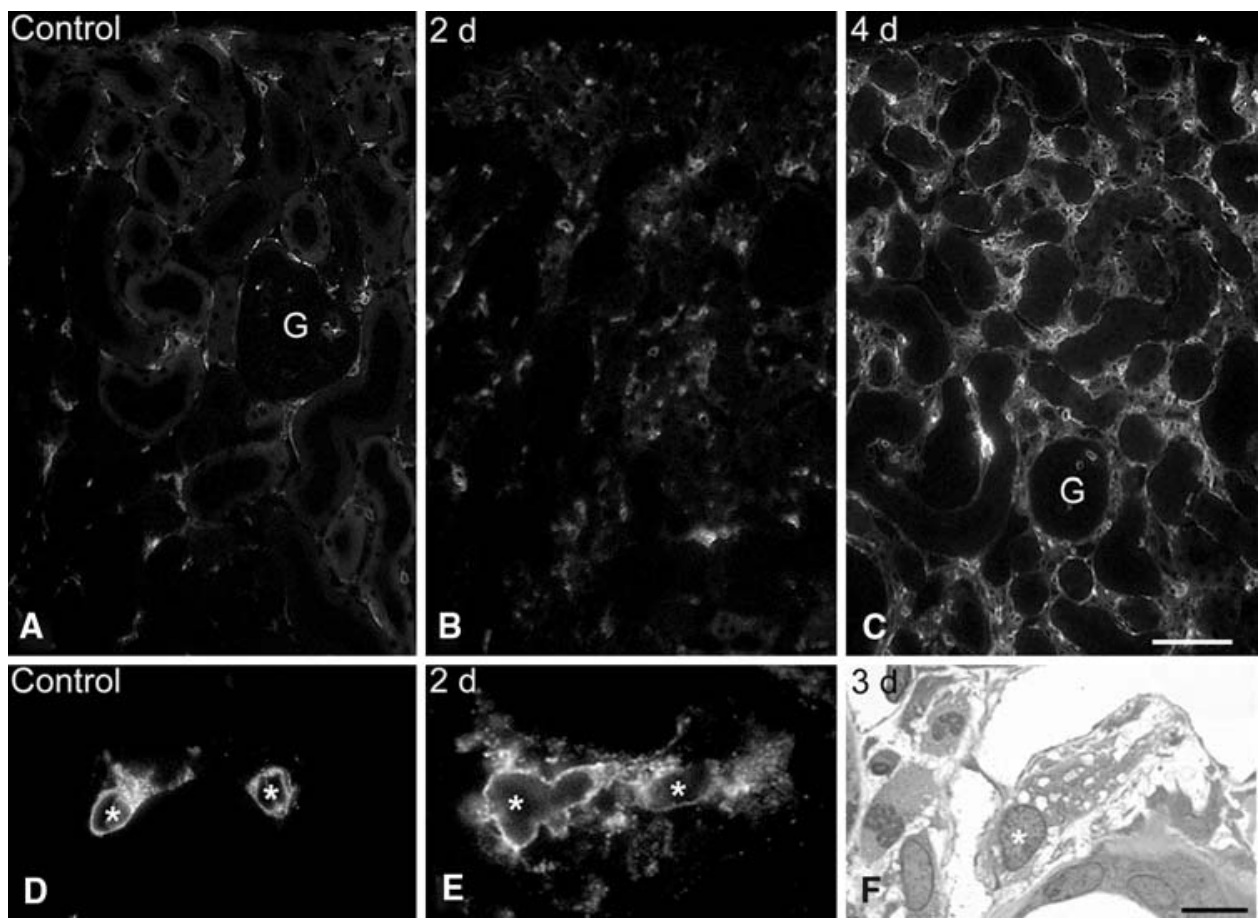

appear lighter than those of fibroblasts and that reveal frequent holes like in a lace-veil (Fig. 10) (Kaissling and Le Hir 1994; Kaissling et al. 1996). In sharp contrast to (myo)fibroblasts dendritic cells lack actin filaments and junctions with other cells.
Massive invasion of mononuclear cells in the obstructed kidney was observed from day 2 after ureter ligature. In the light- and the electron microscope most infiltrating cells in the occluded kidneys displayed the morphology of dendritic cells, of lymphocytes, or of macrophages. Frequency 
and size of dendritic cells increased dramatically during the 4 days of ureteral obstruction (Fig. 10).

\section{FSP1/S100A4-positive cells (FSP1/S100A4)}

FSP1/S100A4 has been implicated in development of renal fibrosis. It had been suggested that proximal tubular cells up-regulate FSP1/S100A4 and transform to myofibroblasts (Iwano et al. 2002). Immunostaining for FSP1/S100A4 (Figs. 11, 12) revealed cells in the interstitial space that displayed the smooth outlines of lymphocytes, as described previously (Le Hir et al. 2005). The abundance of these cells was low in control kidneys and increased sharply on day 2 after ligature and thereafter remained approximately stable (Fig. 10b, c). Occasionally these cells were found also within the lumen of capillaries and venules, as well as within glomeruli. In no instance we observed FSP1/ S100A4 positive tubular cells or cells, double positive either for FSP1/S100A4 and 5'NT or for FSP1/S100A4 and $\alpha$ SMA (Fig. 12).

\section{Proliferation of interstitial cells}

Mitoses in interstitial cells are rarely encountered in control kidneys. Thus, the occurrence of numerous mitoses within the interstitial space after ureteral ligature was particularly striking. All stages of mitoses were found in the light(Fig. 1) and electron microscope (Fig. 13) and by immunofluorescence (Fig. 14) in all types of interstitial cells. Immunostaining for phospho-S-kinase, which is up regulated in the cytoplasm in all stages of mitosis (Fig. 14c), was helpful for easy spotting of mitoses at low magnification (Schmidt et al. 2007).

Quantitative analysis of mitotic interstitial cells in $1 \mu \mathrm{m}$ epon sections showed a sharp increase of the mitotic index in the peritubular interstitium on day 2 in UUO (Fig. 15a).
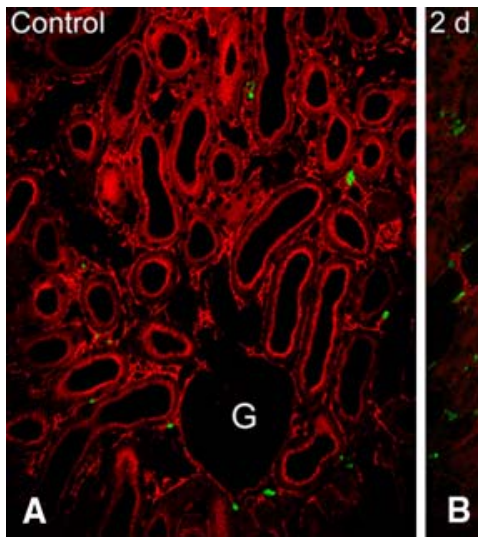

Fig. 11 FSP1/S100A4-positive cells in the renal cortex. $3 \mu \mathrm{m}$ cryostat sections, immonofluorescence; 5'NT—red channel; FSP 1/S100A4green channel. In controls a very few FSP1/S100A4-positive cells are seen in the peritubular interstitium among the 5'NT-positive interstitial cells; the abundance of FSP1/S100A4 positive cells in the interstitial spaces increases at day 2 and 3 after ureteral obstruction; a few are found in glomeruli $(G)$; arterioles (arrow) are weakly labeled by the antibody to FSP1/S100A4, tubular epithelia are negative for FSP1/ S100A4. Bar $\sim 100 \mu \mathrm{m}$
Fig. 12 FSP $1 /$ S $100 A 4$ and $\alpha$ SMA in renal cortex after 4 days of ureteral obstruction. $3 \mu \mathrm{m}$ cryostat sections, immonofluorescence; red channelFSP1/S100A4, green channelaSMA; FSP1/S100A4-positive cells in the interstitial space never stained for $\alpha \mathrm{SMA}$; tubular profiles never stained for FSP1/ S100A4 or $\alpha$ SMA; $(G)$-glomerulus, insert: at higher magnification the shapes of FSP1/ S100A4-positive cells suggest that they are lymphocytes and not fibroblasts. Bar $\sim 100 \mu \mathrm{m}$; insert $\sim 10 \mu \mathrm{m}$
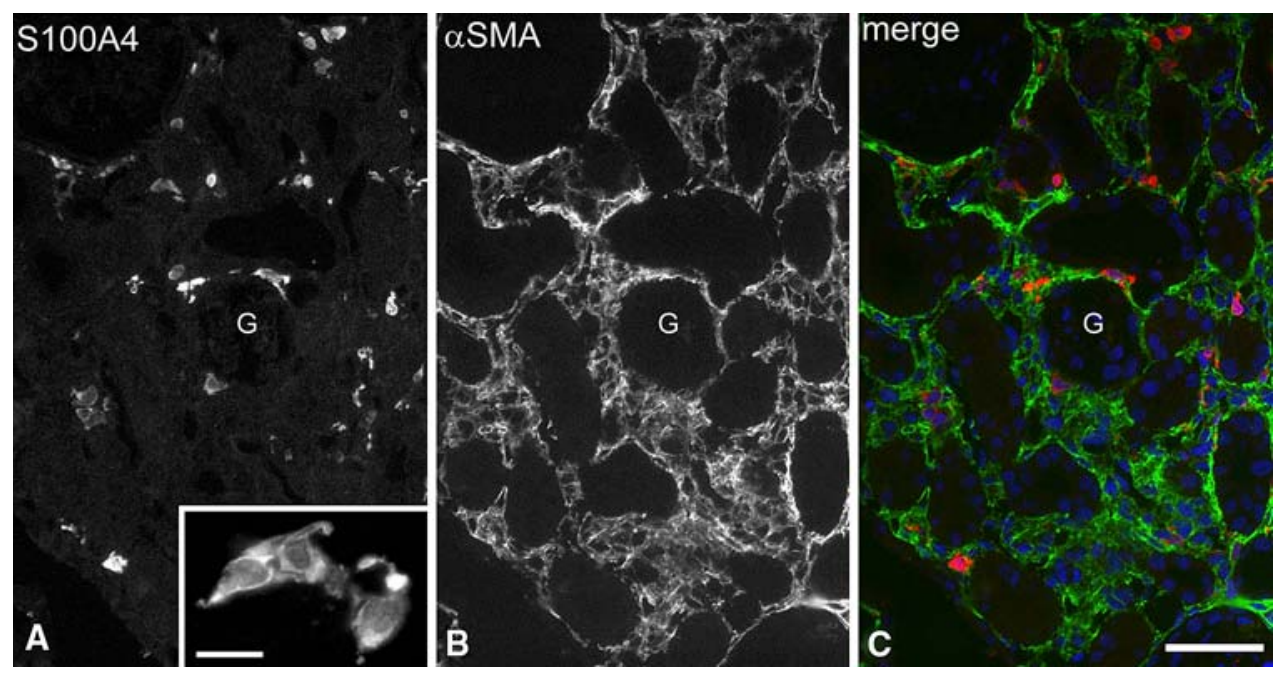


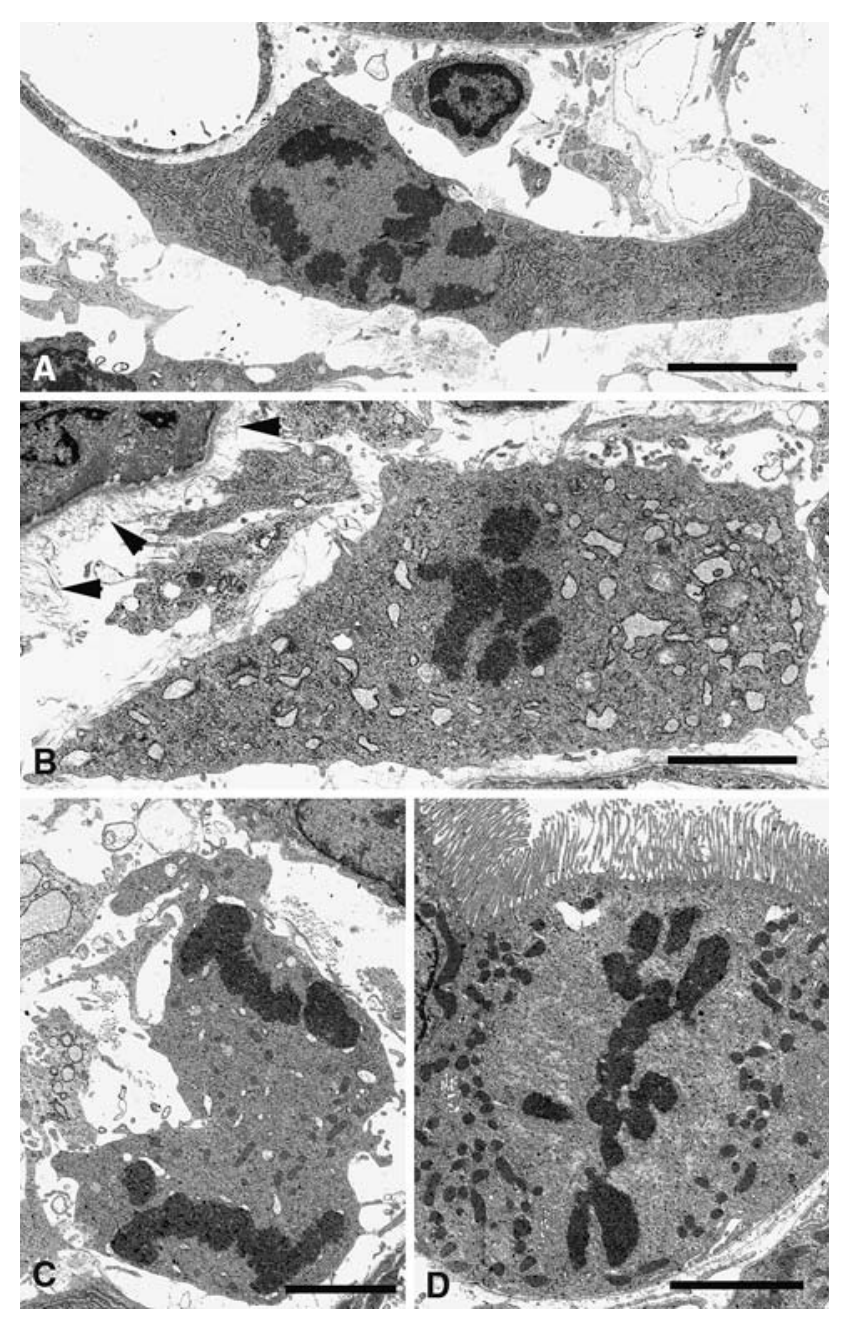

Fig. 13 Mitotic figures in ureter-ligated kidneys on day 2; $80 \mathrm{~nm}$ epon sections. The fibroblast in a (prophase) displays a rather normal morphology with its close association with a capillary (upper left corner); the RER appears abnormally abundant but the shape of the cisterns is not altered. The fibroblasts in $\mathbf{b}$ shows inflated cisterns of RER. Note the abundance of collagen fibrils along the basement membrane of the tubule (arrowheads, compare with Fig. 9). The mononuclear cell in $\mathbf{c}$ cannot be precisely identified. d Proximal tubular cell. Bars $4 \mu \mathrm{m}$. Bars $\sim 100 \mu \mathrm{m}$ and $10 \mu \mathrm{m}$

Thereafter the mitotic index decreased but it remained significantly higher in the occluded kidney at days 3 and 4 than in controls. Even though up to $20 \%$ of mitotic cells could not be identified it was evident that fibroblasts and mononuclear cells contributed similarly to the increase. This was confirmed by electron microscopy (Fig. 13), since of a total of 32 mitotic cells found on days 2, 3 and 4 in the interstitium, 17 were fibroblasts and 15 mononuclear cells.

In the electron microscope mitotic figures were seen in fibroblasts with normal RER as well as in fibroblasts with inflated RER (Fig. 13). In fluorescence microscopy mitotic figures in fibroblasts were independent of the levels of expression of 5'NT and $\alpha$ SMA (Fig. 14). Thus, cell prolif- eration affected the various stages of transformation of fibroblasts in myofibroblasts.

Mitotic figures in tubules and in capillaries were rare in control kidneys. They were easily found in occluded kidneys on day 2, and less so on days 1, 3 and 4. Quantification was not carried out.

\section{Discussion}

The main purpose of the present study was to investigate the early response to ureter obstruction of resident fibroblasts in the renal cortex. Two major alterations were observed, starting from the first day after ligature of the ureter in the rat. Firstly, ultrastructural features and the expression of specific proteins suggested the progressive acquisition by virtually all fibroblasts of characteristic features of myofibroblasts. Because the transformation did not affect all fibroblasts simultaneously a large heterogeneity in the phenotypes of fibroblasts was present. Secondly, the incidence of mitosis of fibroblasts increased dramatically, affecting the various phenotypes of fibroblasts.

Transformation of resident fibroblasts to the myofibroblast phenotype

Immunofluorescence data as well as ultrastructural data showed the acquisition by resident fibroblasts of features of myofibroblasts. In immunofluorescence cortical interstitial fibroblasts were identified in the present study by their expression of 5'NT (Kaissling and Le Hir 1994; Kaissling et al. 1996; Le Hir et al. 2005). Co expression of 5'NT with $\alpha$ SMA was never observed in interstitial cells of control or contralateral kidneys but appeared already on day 1 after UUO, and became progressively more frequent up to day 4, where nearly all 5'NT-positive fibroblasts expressed more or less strongly $\alpha$ SMA. Thus, it appears that during the first days of UUO virtually all resident fibroblasts acquired the most characteristic feature of myofibroblats.

In the electron microscope the increased size of cisterns of RER suggested an increased production of extracellular matrix proteins by fibroblasts of obstructed kidneys. This also is a feature of the transformation of fibroblasts into myofibroblasts (Desmouliere et al. 2005; Hinz 2007; Hinz et al. 2007). Accordingly, the incidence of collagen fibrils was markedly increased in the interstitium after day 3 and 4 days of UUO. The presence of intercellular junctions is considered characteristic for myofibroblasts (Powell et al. 1999). It must be stressed that previously junctions were found between interstitial fibroblasts of normal rat kidneys (Kaissling and Le Hir 1994; Kaissling et al. 1996). However, in the present study they were much more easily found in obstructed kidneys compared to control or contra- 
Fig. 14 Mitotic cells in the peritubular interstitium in ureterligated kidneys. $3 \mu \mathrm{m}$ cryostat sections, immonofluorescence; $\alpha \mathrm{SMA}$ - green channel; 5'NT, or phopho-S6 kinase (p-S6 K) red channel, chromatin staining by DAPI-blue channel. The mitotic cell in a heavily expresses $5^{\prime} \mathrm{NT}$ and faintly $\alpha \mathrm{SMA}$, the adjacent cell shows strong $\alpha$ SMA and faint $5^{\prime} \mathrm{NT}$ staining. The two mitotic cells in B display strong staining for $\alpha \mathrm{SMA}$ along the plasma membrane and in the cell processes, $5^{\prime} \mathrm{NT}$ staining appears granular and is seen over the cytoplasm. The mitotic cell in $\mathrm{C}$ shows strong $\alpha \mathrm{SMA}$ along the plasma membrane, in the cell processes and in a reticulated manner also in the cytoplasm; p-S6 K is up regulated in the cytoplasm of mitotic cells, whereas in quiescent cells the nucleus shows weak staining. Bar $\sim 10 \mu \mathrm{m}$
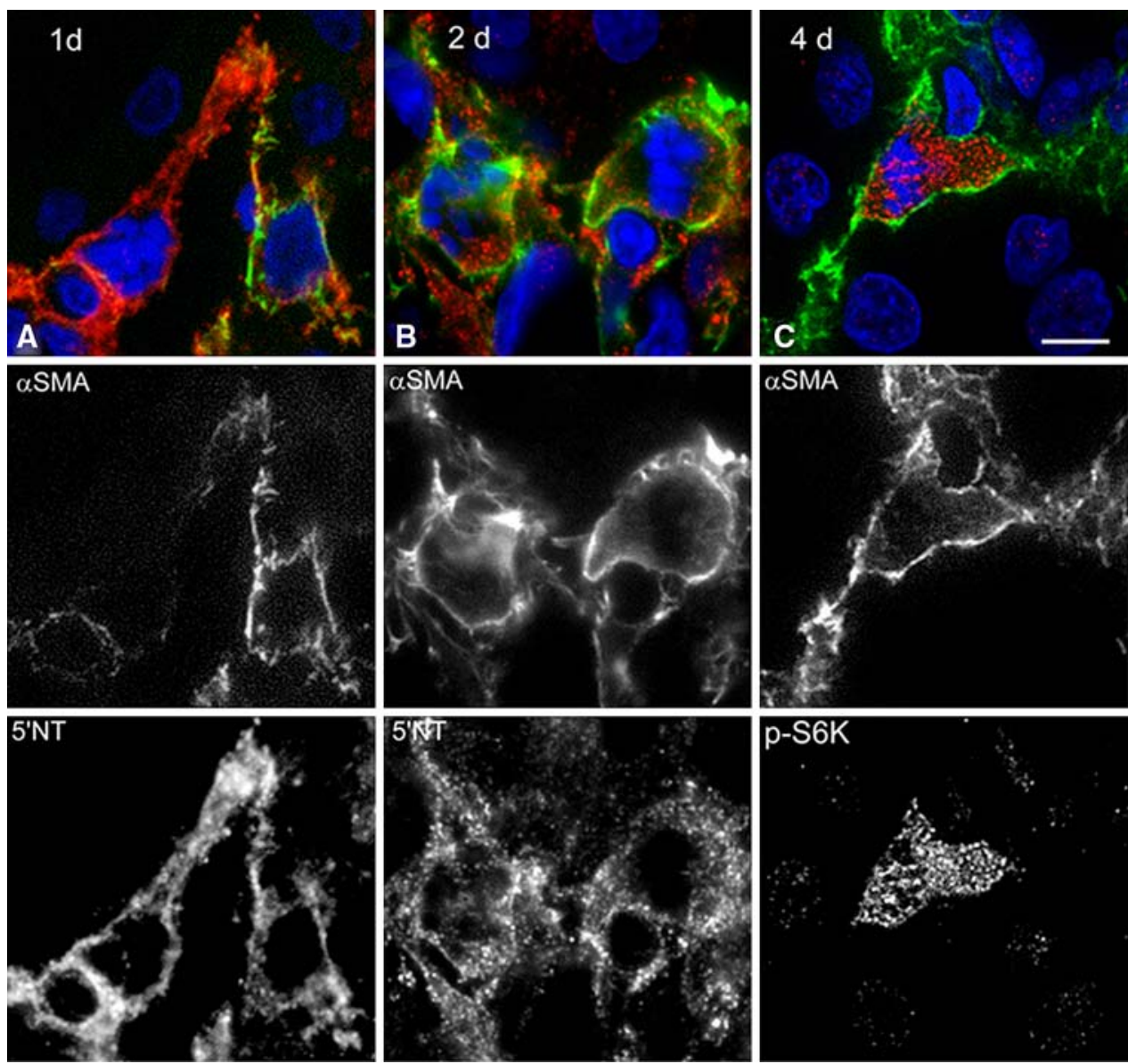

lateral kidneys. These collected data suggest that the different shapes and phenotypes of fibroblasts seen in obstructed kidneys are different functional stages of one cell type. The striking differences between neighboring fibroblasts pertaining to the general cell morphology, to the abundance and shape of cisterns of RER and to the expression of $5^{\prime} \mathrm{NT}, \alpha \mathrm{SMA}$ and vimentin in obstructed kidneys suggest that alterations of fibroblasts following UUO are not attributable only to diffusible factors, for example secreted by infiltrating mononuclear cells. Forces exerted on individual cells might play a role as well. Indeed, a study of uranyl acetate-induced acute renal failure in rats (Fujigaki et al. 2005) suggested that forces exerted on fibroblasts are responsible for expression of $\alpha \mathrm{SMA}$ in fibroblasts around dilated tubules and that under this condition myofibroblasts are derived from the progressive transformation of resident fibroblasts. Transformation of 5'NT-positive fibroblasts to the myofibroblast phenotype with expression of $\alpha \mathrm{SMA}$ and vimentin was observed also around dilated, damaged distal convoluted tubules after treatment with thiazides (Loffing et al. 1996; Le Hir et al. 2005). The role of the tension exerted on stress fibers in the differentiation of myofibroblasts has been discussed recently (Hinz 2007).
Controversial identity of FSP1/S100A4-expressing cells

As found before (Anders et al. 2002; Iwano et al. 2002), in the present study UUO resulted in an increased incidence of FSP1/S100A4-positive cells in the renal cortical interstitium. In previous studies those cells were considered as fibroblasts/ myofibroblasts (Anders et al. 2002; Iwano et al. 2002). That interpretation is not supported by our observations since we did not find cells double positive for FSP 1 and $\alpha$ SMA or $5^{\prime} \mathrm{NT}$ in UUO. Similarly, in polycystic kidneys in mice (Okada et al. 2000) and in TGF over-expression-driven fibrosis in mice (Chai et al. 2003) FSP1-positive cells were generally negative for $\alpha$ SMA. Furthermore in the present study the FSP1-positive cells were generally ovoid with one or two plump cell processes. Finally frequent FSP1-positive cells adhered at the luminal aspect of endothelia. Thus FSP1-positive cells are probably not myofibroblasts but rather infiltrating leukocytes as found in a previous study (Le Hir et al. 2005).

Proliferation of interstitial cells

The increased abundance of fibroblasts in the UUO kidneys may be explained by the proliferation of resident cells, with no need for the extra-renal source proposed by others 



Fig. 15 Quantitative analysis of mitotic cells in the interstitium in response to UUO. a Overall mitotic rates in interstitial cells. Values on day 1,2, 3 and 4 differ significantly from values of controls. b Relative contribution of fibroblasts and mononuclear cells to mitotic activity in the interstitium. Means \pm standard deviation; $n=3$

(Broekema et al. 2007; Li et al. 2007). Indeed, a peak of mitotic activity was observed on day 2 in tubular, vascular and interstitial cells. This is in agreement with the time course described in the same model in a previous study (Pat et al. 2005). Duymelinck et al. (Duymelinck et al. 2000) observed a peak in Ki-67-positive cells in $\alpha$ SMA-positive myofibroblasts in rats at day 5 after UUO. Also the nuclear incorporation (Hughes et al. 1999) of bromo-2'-deoxyuridine in $\alpha$ SMA-positive interstitial cells in a mouse model of UUO strongly suggested proliferation of myofibroblasts (Hughes et al. 1999). This is clearly confirmed by the detection of mitotic figures in the present study. Mitoses were found in cells with various levels of $\alpha$ SMA and $5^{\prime} \mathrm{NT}$. In the electron microscope some mitotic fibroblasts displayed a normal RER, others an inflated RER. Thus, proliferation was not restricted to a specific stage of differentiation of fibroblasts. The origin of mitotic factors might be infiltrating cells but also tubular cells. The latter produce M-CSF in the UUO model in rats (Isbel et al. 2001).

Changes of tubular morphology

A further observation was made, which is highly relevant to the discussion about the role of EMT in renal fibrosis: whereas distal and proximal tubules in the cortex displayed profound regressive and atrophic alterations after ureter ligature, they preserved their epithelial architecture. In other words there was no morphological evidence of EMT during the 4 days following UUO. The dilatation of distal tubules following UUO has been reported before (Kida and Sato 2007). We found that the major morphological alterations in the proximal tubule are cellular atrophy accompanied by decreased luminal and outer diameters, affecting a majority of, but not all nephrons. The role of atrophic tubules in development of interstitial fibrosis has been pointed out in a rat model for renal failure, induced by disturbance of microcirculation following microsphere injection (Suzuki et al. 2001) and in a model using administration of aristolochic acid (Pozdzik et al. 2008). The signals, implicated in activation, proliferation and transformation of resident fibroblasts to myofibroblasts are among others TGF $\beta$ and PDGF-D, produced and released by damaged tubules (Suzuki et al. 2001; Taneda et al. 2003; Forino et al. 2006; Pozdzik et al. 2008). Tubular shrinkage affected also the distal segments of some nephrons. Virtually identical tubular alterations occurred in nephrons in which urine flow was decreased as a consequence of obstruction of the urinary pole by crescents in models of glomerular diseases (Le Hir and Besse-Eschmann 2003; Kriz and LeHir 2005).

Also previous other studies showed that fibrosis developed and myofibroblasts appeared without contribution of EMT in nephritic syndrome in humans (Kuusniemi et al. 2005) and in laboratory animals (Duymelinck et al. 2000; Fujigaki et al. 2005; Pozdzik et al. 2008). A similar conclusion was drawn from a rat model of angiotensin II-induced renal fibrosis (Faulkner et al. 2005) and a murine model (Chai et al. 2003).

In other studies FSP1 was detected by immunofluorescence in tubules of obstructed kidneys in animal models of UUO (Iwano et al. 2002; Kida et al. 2007; Sakairi et al. 2007). This finding was interpreted as evidence of EMT. We never detected FSP1 in tubular cells in the present study. It must be noted that in the previous studies tubular immunoreactivity for FSP1 was shown only on day 7 after ureter ligature or later, whereas our study ended on day 4.

In conclusion, during the first days following ureter ligature the resident peritubular fibroblasts differentiate into myofibroblasts and they proliferate strongly. These events are likely essential to fibrosis in UUO.

Acknowledgments We thank Gery Barmettler, Michelle Enderlin and Margrit Müller for excellent technical assistance. The investigation was supported by "Stiftung für Wissenschaftliche Forschung an der Universität" Zürich. 
Open Access This article is distributed under the terms of the Creative Commons Attribution Noncommercial License which permits any noncommercial use, distribution, and reproduction in any medium, provided the original author(s) and source are credited.

\section{References}

Anders HJ, Vielhauer V, Frink M, Linde Y, Cohen CD, Blattner SM, Kretzler M, Strutz F, Mack M, Grone HJ, Onuffer J, Horuk R, Nelson PJ, Schlondorff D (2002) A chemokine receptor CCR-1 antagonist reduces renal fibrosis after unilateral ureter ligation. J Clin Invest 109:251-259

Broekema M, Harmsen MC, van Luyn MJ, Koerts JA, Petersen AH, van Kooten TG, van Goor H, Navis G, Popa ER (2007) Bone marrow-derived myofibroblasts contribute to the renal interstitial myofibroblast population and produce procollagen I after ischemia/reperfusion in rats. J Am Soc Nephrol 18:165-175

Chai Q, Krag S, Chai S, Ledet T, Wogensen L (2003) Localisation and phenotypical characterisation of collagen-producing cells in TGF-beta 1-induced renal interstitial fibrosis. Histochem Cell Biol 119:267-280

Dawson TP, Gandhi R, Le Hir M, Kaissling B (1989) Ecto-5' -nucleotidase: localization in rat kidney by light microscopic histochemical and immunohistochemical methods. J Histochem Cytochem 37:39-47

Desmouliere A, Chaponnier C, Gabbiani G (2005) Tissue repair, contraction, and the myofibroblast. Wound Repair Regen 13:7-12

Dong X, Swaminathan S, Bachman LA, Croatt AJ, Nath KA, Griffin MD (2005) Antigen presentation by dendritic cells in renal lymph nodes is linked to systemic and local injury to the kidney. Kidney Int 68:1096-1108

Duymelinck C, Dauwe SE, De Greef KE, Ysebaert DK, Verpooten GA, De Broe ME (2000) TIMP-1 gene expression and PAI-1 antigen after unilateral ureteral obstruction in the adult male rat. Kidney Int 58:1186-1201

Essawy M, Soylemezoglu O, Muchaneta-Kubara EC, Shortland J, Brown CB, el Nahas AM (1997) Myofibroblasts and the progression of diabetic nephropathy. Nephrol Dial Transplant 12:43-50

Faulkner JL, Szcykalski LM, Springer F, Barnes JL (2005) Origin of interstitial fibroblasts in an accelerated model of angiotensin II-induced renal fibrosis. Am J Pathol 167:1193-1205

Forino M, Torregrossa R, Ceol M, Murer L, Vella MD, Prete DD, D'Angelo A, Anglani F (2006) TGFbeta1 induces epithelial-mesenchymal transition, but not myofibroblast transdifferentiation of human kidney tubular epithelial cells in primary culture. Int J Exp Pathol 87:197-208

Fujigaki Y, Muranaka Y, Sun D, Goto T, Zhou H, Sakakima M, Fukasawa H, Yonemura K, Yamamoto T, Hishida A (2005) Transient myofibroblast differentiation of interstitial fibroblastic cells relevant to tubular dilatation in uranyl acetate-induced acute renal failure in rats. Virchows Arch 446:164-176

Gandhi R, Le Hir M, Kaissling B (1990) Immunolocalization of ecto5 '-nucleotidase in the kidney by a monoclonal antibody. Histochemistry $95: 165-174$

Hinz B (2007) Formation and function of the myofibroblast during tissue repair. J Invest Dermatol 127:526-537

Hinz B, Phan SH, Thannickal VJ, Galli A, Bochaton-Piallat ML, Gabbiani G (2007) The Myofibroblast. One Function, Multiple Origins. Am J Pathol 170:1807-1816

Hughes J, Brown P, Shankland SJ (1999) Cyclin kinase inhibitor p21CIP1/WAF1 limits interstitial cell proliferation following ureteric obstruction. Am J Physiol 277:F948-F956

Isbel NM, Hill PA, Foti R, Mu W, Hurst LA, Stambe C, Lan HY, Atkins RC, Nikolic-Paterson DJ (2001) Tubules are the major site of
M-CSF production in experimental kidney disease: correlation with local macrophage proliferation. Kidney Int 60:614-625

Iwano M, Neilson EG (2004) Mechanisms of tubulointerstitial fibrosis. Curr Opin Nephrol Hypertens 13:279-284

Iwano M, Plieth D, Danoff TM, Xue C, Okada H, Neilson EG (2002) Evidence that fibroblasts derive from epithelium during tissue fibrosis. J Clin Invest 110:341-350

Kaissling B, Le Hir M (1994) Characterization and distribution of interstitial cell types in the renal cortex of rats. Kidney Int 45:709-720

Kaissling B, Hegyi I, Loffing J, Le Hir M (1996) Morphology of interstitial cells in the healthy kidney. Anat Embryol (Berl) 193:303318

Kida Y, Sato T (2007) Tubular changes in obstructed kidney of adult mice evaluated using immunohistochemistry for segment-specific marker. Histol Histopathol 22:291-303

Kida Y, Asahina K, Teraoka H, Gitelman I, Sato T (2007) Twist Relates to Tubular Epithelial-Mesenchymal Transition and Interstitial Fibrogenesis in the Obstructed Kidney. J Histochem Cytochem 55(7):661-673

Kriz W, LeHir M (2005) Pathways to nephron loss starting from glomerular diseases-insights from animal models. Kidney Int 67:404-419

Kuusniemi AM, Lapatto R, Holmberg C, Karikoski R, Rapola J, Jalanko H (2005) Kidneys with heavy proteinuria show fibrosis, inflammation, and oxidative stress, but no tubular phenotypic change. Kidney Int 68:121-132

Lan HY (2003) Tubular epithelial-myofibroblast transdifferentiation mechanisms in proximal tubule cells. Curr Opin Nephrol Hypertens 12:25-29

Le Hir M, Besse-Eschmann V (2003) A novel mechanism of nephron loss in a murine model of crescentic glomerulonephritis. Kidney Int 63:591-599

Le Hir M, Hegyi I, Cueni-Loffing D, Loffing J, Kaissling B (2005) Characterization of renal interstitial fibroblast-specific protein $1 /$ S100A4-positive cells in healthy and inflamed rodent kidneys. Histochem Cell Biol 123:335-346

Li J, Deane JA, Campanale NV, Bertram JF, Ricardo SD (2007) The contribution of bone marrow-derived cells to the development of renal interstitial fibrosis. Stem Cells 25:697-706

Liu Y (2004) Epithelial to mesenchymal transition in renal fibrogenesis: pathologic significance, molecular mechanism, and therapeutic intervention. J Am Soc Nephrol 15:1-12

Loffing J, Loffing-Cueni D, Hegyi I, Kaplan MR, Hebert SC, Le Hir M, Kaissling B (1996) Thiazide treatment of rats provokes apoptosis in distal tubule cells. Kidney Int 50:1180-1190

Marxer-Meier A, Hegyi I, Loffing J, Kaissling B (1998) Postnatal maturation of renal cortical peritubular fibroblasts in the rat. Anat Embryol (Berl) 197:143-153

Mucsi I, Rosivall L (2007) Epithelial-mesenchymal transition in renal tubular cells in the pathogenesis of progressive tubulo-interstitial fibrosis. Acta Physiol Hung 94:117-131

Okada H, Ban S, Nagao S, Takahashi H, Suzuki H, Neilson EG (2000) Progressive renal fibrosis in murine polycystic kidney disease: an immunohistochemical observation. Kidney Int 58:587-597

Pat B, Yang T, Kong C, Watters D, Johnson DW, Gobe G (2005) Activation of ERK in renal fibrosis after unilateral ureteral obstruction: modulation by antioxidants. Kidney Int 67:931-943

Powell DW, Mifflin RC, Valentich JD, Crowe SE, Saada JI, West AB (1999) Myofibroblasts I. Paracrine cells important in health and disease. Am J Physiol 277:C1-9

Pozdzik AA, Salmon IJ, Debelle FD, Decaestecker C, Van den Branden C, Verbeelen D, Deschodt-Lanckman MM, Vanherweghem JL, Nortier JL (2008) Aristolochic acid induces proximal tubule apoptosis and epithelial to mesenchymal transformation. Kidney Int 73.595-607 
Remuzzi G, Bertani T (1998) Pathophysiology of progressive nephropathies. N Engl J Med 339:1448-1456

Roufosse C, Bou-Gharios G, Prodromidi E, Alexakis C, Jeffery R, Khan S, Otto WR, Alter J, Poulsom R, Cook HT (2006) Bone marrow-derived cells do not contribute significantly to collagen I synthesis in a murine model of renal fibrosis. J Am Soc Nephrol 17:775-782

Sakairi T, Hiromura K, Yamashita S, Takeuchi S, Tomioka M, Ideura H, Maeshima A, Kaneko Y, Kuroiwa T, Nangaku M, Takeuchi T, Nojima Y (2007) Nestin expression in the kidney with an obstructed ureter. Kidney Int 72:307-318

Schmidt T, Wahl P, Wuthrich RP, Vogetseder A, Picard N, Kaissling B, Le Hir M (2007) Immunolocalization of phospho-S6 kinases: a new way to detect mitosis in tissue sections and in cell culture. Histochem Cell Biol 127:123-129
Soos TJ, Sims TN, Barisoni L, Lin K, Littman DR, Dustin ML, Nelson PJ (2006) CX3CR1+ interstitial dendritic cells form a contiguous network throughout the entire kidney. Kidney Int 70:591-596

Suzuki T, Kimura M, Asano M, Fujigaki Y, Hishida A (2001) Role of atrophic tubules in development of interstitial fibrosis in microembolism-induced renal failure in rat. Am J Pathol 158:75-85

Taneda S, Hudkins KL, Topouzis S, Gilbertson DG, Ophascharoensuk V, Truong L, Johnson RJ, Alpers CE (2003) Obstructive uropathy in mice and humans: potential role for PDGF-D in the progression of tubulointerstitial injury. J Am Soc Nephrol 14:2544-2555

Zeisberg M, Strutz F, Muller GA (2001) Renal fibrosis: an update. Curr Opin Nephrol Hypertens 10:315-320 